\title{
Vivienda y servicios básicos en Tungurahua
}

\section{Estructura actual}

La ausencia de vivienda en general se constituye un problema social muy complejo de resolver; los hogares con bajos ingresos y/o quienes emigran desde la zona rural a residir permanentemente en la ciudad son los más afectados, y su adquisición constituye una inversión considerable para las familias tungurahuenses, sin embargo, poseer una vivienda digna sin lugar a dudas constituye una recompensa gratificante al sacrificio y constancia en el trabajo y ahorro diario, recompensa a los que muchos no pueden acceder por varios motivos.

Para realizar este análisis se ha tomado los resultados obtenidos por el INEC a través de la Encuesta de Condiciones de Vida-ECV, Sexta Ronda 2013-2014. Para Tungurahua la muestra corresponde a 1.164 viviendas, en 97 sectores de la provincia. De esta muestra provincial, la zona rural tiene $64 \%$ y la zona urbana el $36 \%$.

De estos totales por zona, el $85 \%$ en la zona rural posee vivienda propia y totalmente pagada y el $51 \%$ en la zona urbana. Sólo un $10 \%$ en la zona rural y el $16 \%$ en la zona urbana habitan en viviendas cedidas; y, un $3 \%$ y $30 \%$ de la zona rural y urbana respectivamente, lo hacen en viviendas arrendadas.

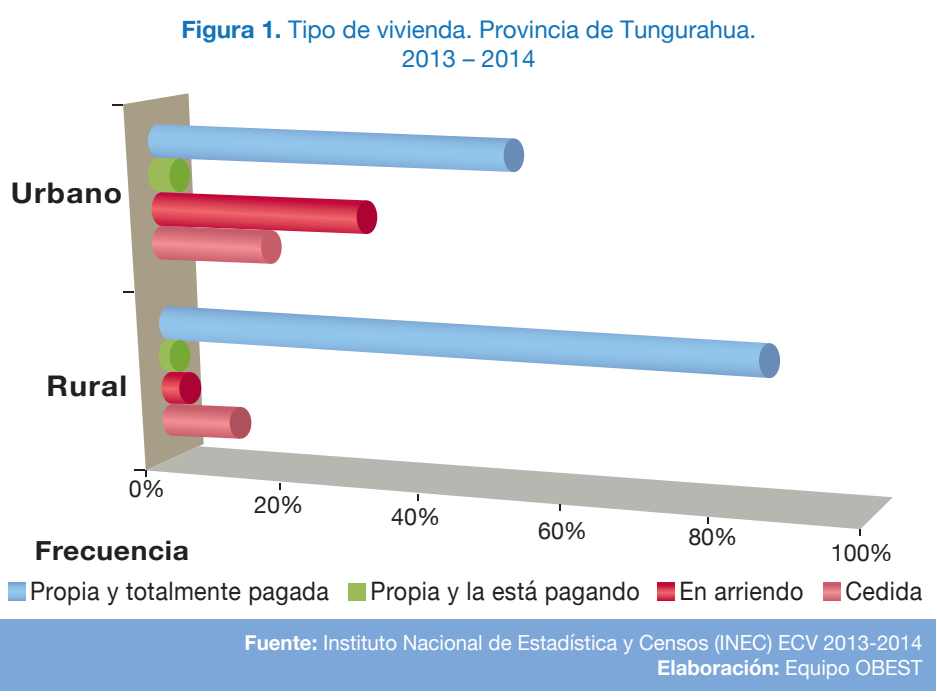

En la figura 2 se puede apreciar los valores mensuales mínimos y máximos pagados por concepto de arriendo tanto en la zona rural como urbana.

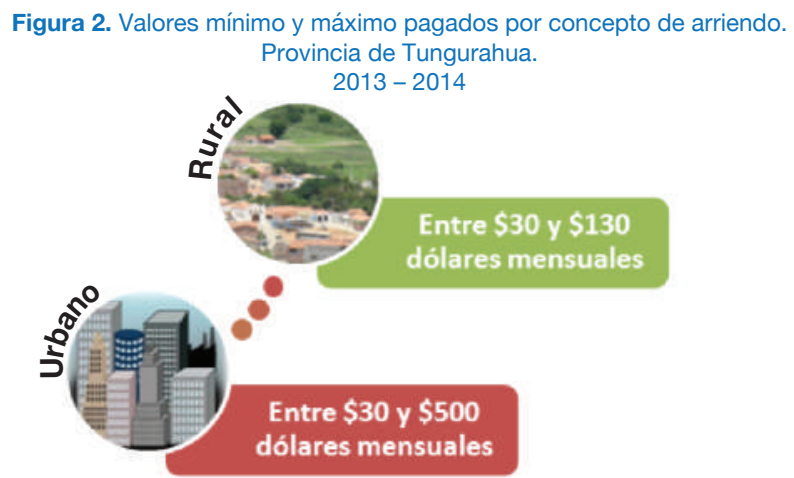

Dentro de la ECV 2013 - 2014 constan preguntas sobre los servicios que dispone la vivienda, a saber: suministro de agua a través de red pública, medidor de energía eléctrica, alcantarillado, eliminación de basura; y otros servicios, como: internet, telefonía fija; y, televisión por cable.

De acuerdo a la figura 3, el $99 \%$ de la zona urbana cuenta con abastecimiento de agua potable a través de red pública dentro de la vivienda y un $84 \%$ en la zona rural. Tan solo el $1 \%$ en la zona urbana obtiene este suministro a través de otras fuentes como carros repartidores; y, el 16\% en la zona rural lo obtiene de otras fuentes o a su vez de ríos, vertientes o acequias.

Figura 3. Formas de abastecimiento de agua. Provincia de Tungurahua. 20132014.

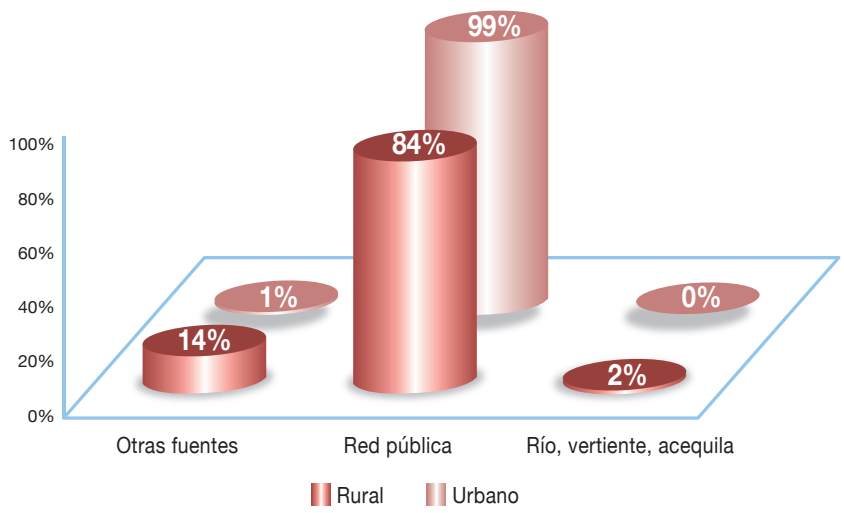

Fuente: Instituto Nacional de Estadística y Censos (INEC) ECV 2013-2014 Elaboración: Equipo OBEST

De igual manera en lo que respecta al suministro de energía eléctrica el $92 \%$ y $83 \%$ de la zona rural y urbana, respectivamente, cuentan con medidor de uso exclusivo para la vivienda; los porcentajes restantes, disponen de un medidor para varias viviendas o no poseen medidor.

Figura 4. Suministro de energía eléctrica a través de medidor. Provincia de Tungurahua. $2013-2014$

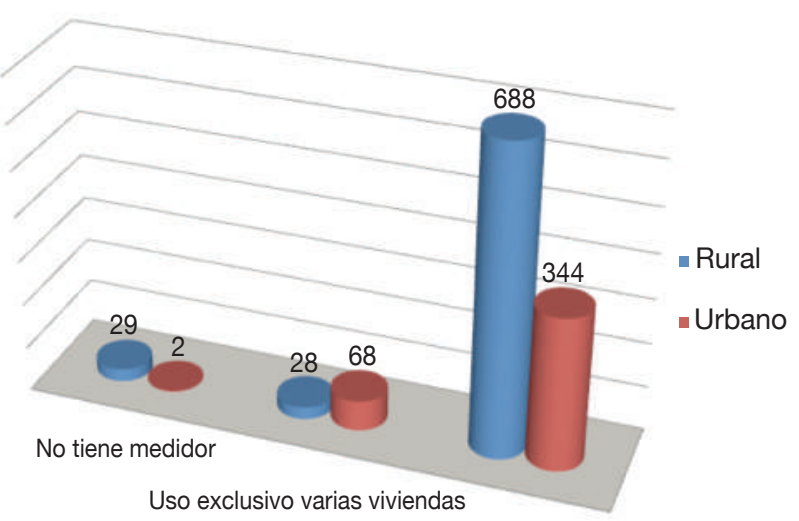

Uso exclusivo para la vivienda

Fuente: Instituto Nacional de Estadística y Censos (INEC) ECV 2013-2014 
La figura 5 muestra la gran diferencia que existe entre el sector urbano y rural, en lo que refiere al servicio de alcantarillado; en el primero el $98 \%$ poseen inodoro con sistema de alcantarillado en sus viviendas, situación que no ocurre en el sector rural, pues los datos confirman que sólo el $42 \%$ cuenta con este servicio dentro de su vivienda; en tanto que, el $22 \%$ y $25 \%$ poseen inodoros con pozo ciego o pozo séptico respectivamente; un 3\% utiliza letrina, y el $8 \%$ no cuenta con ninguna de estas formas de drenaje de aguas residuales.

Figura 5. Servicio de Alcantarillado. Provincia de Tungurahua. $2013-2014$

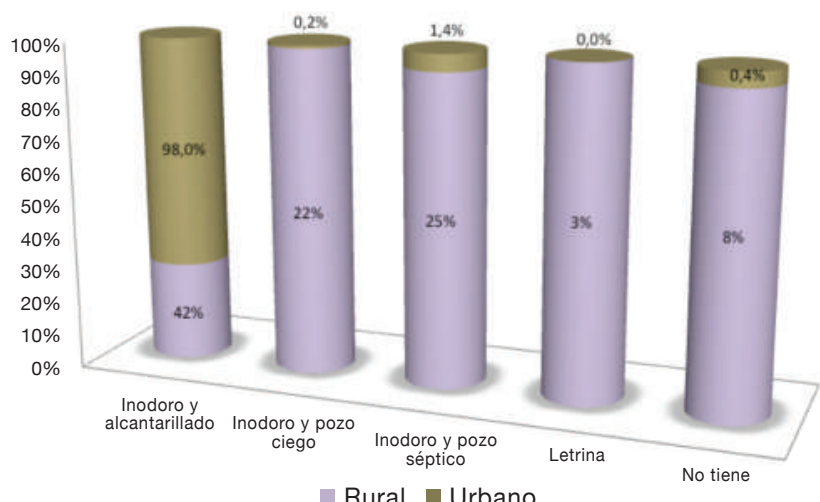

Fuente: Instituto Nacional de Estadistica y Censos (INEC) ECV 2013-2014 Elaboración: Equipo OBEST

En la figura 6 se puede visualizar que en la zona urbana de la provincia el $99,28 \%$ elimina la basura a través del servicio municipal, esto considerando que en esta zona existen los denominados "eco tachos", en donde se puede colocar las fundas de basura hasta su acopio a través del carro recolector. En tanto que, en la zona rural, el mismo llega al $63 \%$ de la población, el resto la elimina a través de otras opciones: quemar (31\%), enterrar (3\%), botar a la calle, quebrada o lotes vacíos (3\%).

Figura 6. Eliminación de basura. Provincia de Tungurahua. $2013-2014$.

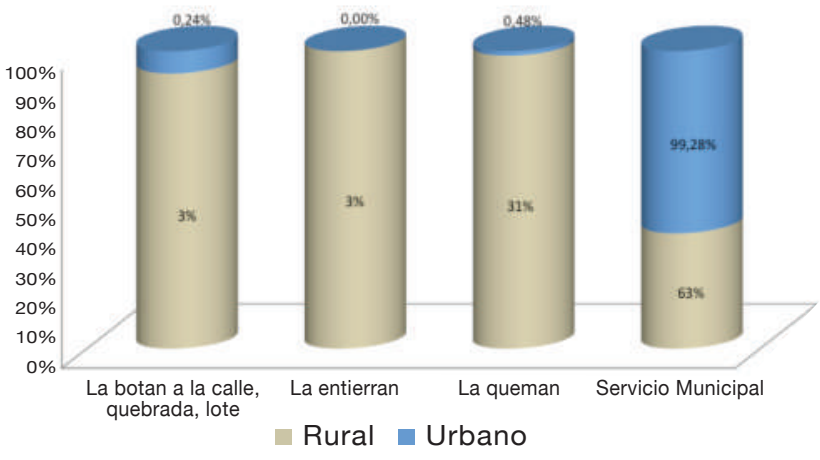

Fuente: Instituto Nacional de Estadística y Censos (INEC) ECV 2013-2014 Elaboración: Equipo OBEST

Otro tipo de servicios que se ha investigado y que actualmente utilizan los hogares son: Internet, televisión por cable y telefonía fija.
La figura 7 indica que en el sector rural solo el $13 \%$ poseen internet en sus viviendas, el $8 \%$ televisión por cable y el $25 \%$ teléfono fijo; mientras que en el sector urbano, el $43 \%$ posee internet, el $26 \%$ televisión por cable y el $65 \%$ teléfono fijo, porcentajes que corresponden a los totales respectivos de las zonas urbana y rural.

Figura 7. Otros servicios. Provincia de Tungurahua. $2013-2014$

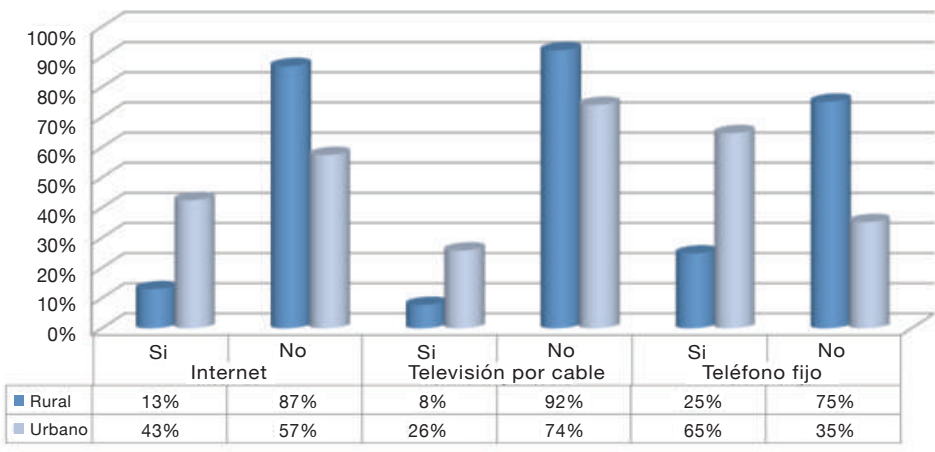

Fuente: Instituto Nacional de Estadística y Censos (INEC) ECV 2013-2014 Elaboración: Equipo OBEST

\section{Referencias:}

- Instituto Nacional de Estadísticas y Censos, Sexta ronda de encuenta de condiciones de vida (ECV) Período 2013 2014, disponible en:http://www.ecuadorencifras.gob.ec/ documentos/web-in-ec/ECV/ECV_2015/documentos/Meto dologia/Documento\%20Metodologico\%20ECV\%206r.PDF

\section{Elaboración:}

Lic. Sandra Garcés Mosquera

Lic. Lorena Rivera Badillo MSc

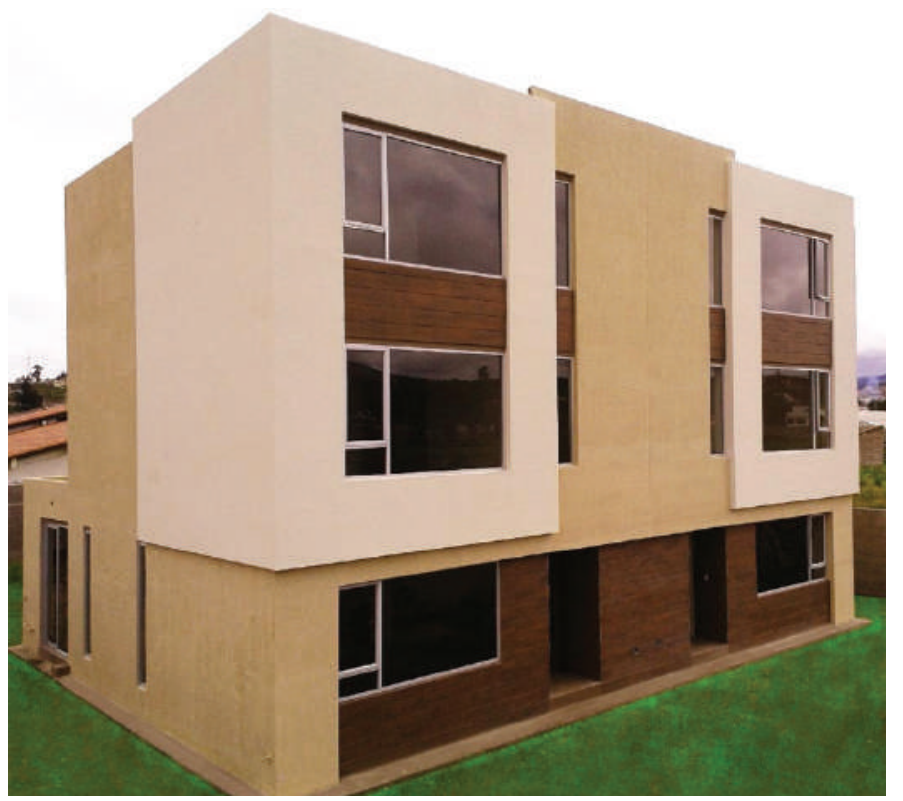

